\title{
ZONALIDADE VERTICAL NO CORPO MINERALIZADO DA MINA DE OURO SCHRAMM (SC) - DETALHAMENTO DO MODELO GENÉTICO
}

\author{
JOÃO CARLOS BIONDI ${ }^{1}$, NILTON D. FRANKE ${ }^{2}$, PAULO R. S. DE CARVALHO ${ }^{2}$ \\ \& SANDRON.VILLANOVA ${ }^{2}$
}

\begin{abstract}
VERTICAL ZONALITY IN THE ORE BODY OF SCHRAMM GOLD MINE - DETALING THE GENETIC MODEL The petrography of ore samples collected from level 140 to 180 of the Schramm gold mine displayed a hydrothermal phase not previously discerned, occurred before the ore genesis, which crystallized magnetite-hydrotermalites. A vertical zonation, was also displayed, characterized by three different ore paragenesis. Bellow level 155, the carbonated ore is hosted by the magnetite-hydrotermalites and it is composed by lamellar hematite, magnetite, sphalerite and gold, with subordinated pyrite, calcopyrite, arsenopyrite, gersdorffite and siegenite. This paragenesis typifies an environment where the primary ore fluid was oxidized and desulphurized, what caused gold deposition. Around the 155 level, the carbonated ore has few sulfides and a paragenesis in which siegenite, gersdorffite and sphalerite are very common minerals, with gold and subordinated pyrite and calcopyrite. At this level ore is hosted by ultrabasic granulites, and gold was deposited as a consequence of the low $\mathrm{pH}$-intermediate $\mathrm{fO}_{2}$ environment. Above the 155 level, the main ore minerals are $\mathrm{Bi}$-rich galena, sphalerite and gold, with subordinated gersdorfite, pirrotite, pyrite and cosalite. Gold is mainly in carbonate but also in quartz veins hosted by granulites. These minerals characterize a reduced fluid and a high $\mathrm{pH}$ environment. The ore body was formed through at least four phases: (1) Genesis of magnetite-hydrothermal veins, at temperatures around $230^{\circ} \mathrm{C}$. (2) Genesis of the oxidized ore inside magnetite-hydrothermal veins and the siegenite-millerite-gersdorffite ore hosted by ultrabasic granulites, at temperatures between $260^{\circ}$ and $310^{\circ} \mathrm{C}$. (3) Period that the main vein stay opened, filled by fluids that precipitated euhedric, prismatic, siderite, quartz and chlorite with little gold, at temperatures between $310^{\circ}$ and $320^{\circ} \mathrm{C}$. (4) With the vein walls coated by minerals crystallized previously, the primary, reduced, ore fluid could not react with host rocks. Gold deposited due the temperature reduction caused by mixing of ore fluid and meteoric water. This new fluid precipitated milky-quartz until the vein closure and the end of the hydrothermal system.
\end{abstract}

Keywords: Schramm Mine (SC-Brazil), gold, shear zone, zonality, genetic model.

Resumo A petrografia de amostras de minério coletadas na mina Schramm entre os níveis 140 e 180 revelou a existência de uma fase hidrotermal anterior a da formação do minério, na qual houve formação de magnetitahidrotermalitos. Mostrou, também, uma zonalidade vertical no minério, caracterizada por três paragêneses distintas. Abaixo de 155 m, o minério é carbonatado, está dentro de magnetita-hidrotermalitos e contém muita hematita lamelar. magnetita, esfalerita e ouro, associados à pirita, calcopirita, arsenopirita, gersdorfita e siegenita. Esta paragênese caracteriza um ambiente no qual o fluido mineralizador foi oxidado e dessulfurizado, o que causou precipitação do ouro. Em torno do nível 155 o minério contém poucos sulfetos em paragênese na qual predominam siegenita, millerita, gersdorfita e esfalerita, com muito ouro e pouca pirita e calcopirita. Nesse horizonte o minério está em meio a granulitos ultrabásicos e o ouro precipitou devido ao ambiente com pH elevado e fO, intermediária. Acima do nível 155 o minério quartzo-carbonatado contém muita galena bismutinífera, esfalerita e ouro, em parte contido no quartzo, associados a gersdorfita, pirrotita, pirita e cosalita. Esta paragênese caracteriza um fluido reduzido, provavelmente com a composição do fluido original, do qual o ouro precipitou, também, devido ao $\mathrm{pH}$ elevado do ambiente. O corpo mineralizado formou-se em ao menos quatro fases: (1) Formação dos filões de magnetita-hidrotermalitos, a temperaturas de cerca de $230^{\circ} \mathrm{C}$. (2) Formação do minério oxidado, dentro dos magnetita-hidrotermalitos, e do minério a siegenitamillerita-gersdorfita, dentro de granulitos ultrabásicos, a temperaturas entre $260^{\circ}$ e $310^{\circ} \mathrm{C}$. (3) Fase na qual a caixa filoneana ficou aberta e houve precipitação de clorita vermicular, siderita e quartzo euédricos, prismáticos, e pouco ouro, a temperaturas entre $310^{\circ} \mathrm{e} 320^{\circ} \mathrm{C}$. (4) Com as paredes da caixa filoneana revestida, o fluido original, redutor, não mais reagiu com as rochas encaixantes e o ouro precipitou devido à diminuição da temperatura do fluido causada pela mistura com águas meteóricas que invadiram o sistema. Houve, então, precipitação de quartzo leitoso até a extinção do sistema hidrotermal.

Palavras-chave: Mina Schramm (SC), ouro, zona de cisalhamento, zonalidade, modelo genético.

INTRODUÇÃO E OBJETIVOS Biondi et al. (2001, 2002a) estudaram a geologia e a petrologia dos minérios e das rochas da mina de ouro Schramm. Esses trabalhos foram feitos com amos- tras coletadas em superfície, na região e no local da mina, e nas galerias do nível $155 \mathrm{~m}$, o único existente na época. Os principais aspectos relatados foram: (a) A mina Schramm destaca-se por 


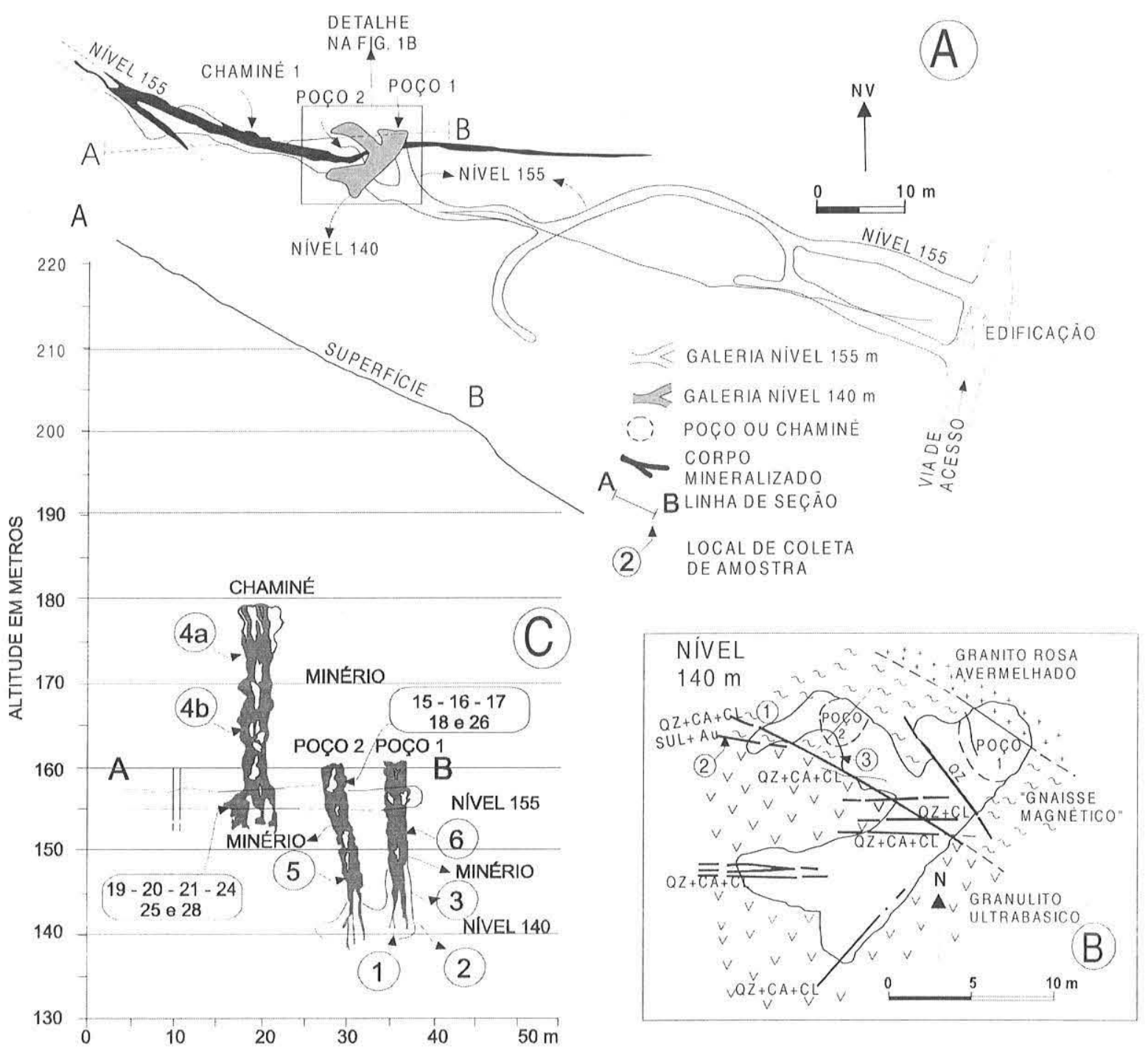

Figura 1 - (A) Planta do nível principal de galerias da mina Schramm, a 155 m, mostrando a localização do veio principal quartzo-carbonático e as posições onde foram lavrados corpos mineralizados com altos teores de Au e Ag (chaminé 1 e poços 1 e 2). (B) Mapa geológico no nível 140 m, onde terminam os poços 1 e 2. (C) Seção esquemática mostrando as formas dos corpos mineralizados lavrados e os números e as posições nas quais foram coletadas as amostras analisadas nesse trabalho. Abreviações: $Q Z=$ quartzo, $C A=$ carbonatos, $C L=$ cloritas, $S U L=$ sulfetos, $A u=$ ouro

estar em uma zona de cisalhamento de alto ângulo e ter ouro associado a uma paragênese com sulfetos de níquel, arsênio e cobalto contidos em veios maciços de siderita-ankerita. (b) $\mathrm{O}$ minério, com 500 e 2.300 ppm de Au, 150 a 300 ppm de Ag, 0, 15 a 0,60\% de As e 0,01 a $1,4 \%$ de $\mathrm{Ni}$, concentra-se somente em carbonatos, contidos em corpos mineralizados alongados, constituídos por veios e amas de carbonatos e quartzo, em meio a granulitos e gnaisses intensa-mente carbonatizados, cloritizados, sericitizados e silicificados. Fora das regiões mineralizadas os teores de Au são menores que $50 \mathrm{ppb}$. (c) A quantidade total de sulfetos é de cerca de $0,5 \%$ da rocha, em volume. No nível 155, a paragênese sulfetada que acompanha o ouro é conposta preponderantemente por siegenita-violarita, millerita e gersdorfita, com pouca esfalerita, pirita níquel-cobaltífera, pirita e pirrotita. Galena, calcopirita, arsenopirita, covelita e um sulfoarseneto de Ni-Fe-Co com fórmula (Co, Fe,
Ni) ${ }_{7.980} \mathrm{As}_{9.000} \mathrm{~S}_{6.000}$, semelhante a gersdorfita, são esporadicos.

Baseados nas características das inclusões fluidas dos minérios da mina Schramm, Biondi \& Xavier (2002) e Biondi et al. (2002a) concluiram que fluido mineralizador primário foi uma solução aquocarbônica, com salinidade entre $0,2 \%$ a $14 \% \mathrm{NaCl}_{\text {equiv, }}$, desprovida de nitrogênio e metano, com muito $\mathrm{CO}_{2}, \mathrm{Fe}, \mathrm{Mg}$ e Cau e $\mathrm{SiO}$, Tinha, também, Cl, Na, K, muito pouco enxofre, os metais $\mathrm{Au}, \mathrm{Ag}, \mathrm{Ni}, \mathrm{As}$ e, em menores proporções, Zn e Co. Biondi et al. (2002a e b) compararam os padrões de fracionamento de elementos terras raras de rochas e minérios do depósito da mina Schramm, e concluiram que, durante a formação do depósito do Schramm, os fluidos hidrotermais reagiram sobretudo com os granulitos ultrabásicos. Nesse mesmo estudo, o uso de cloritas como geotermômetro e o relacionamento das temperaturas de cristalização com as isócoras deduzidas da microtermometria de inclusões fluidas, permitiu de- 

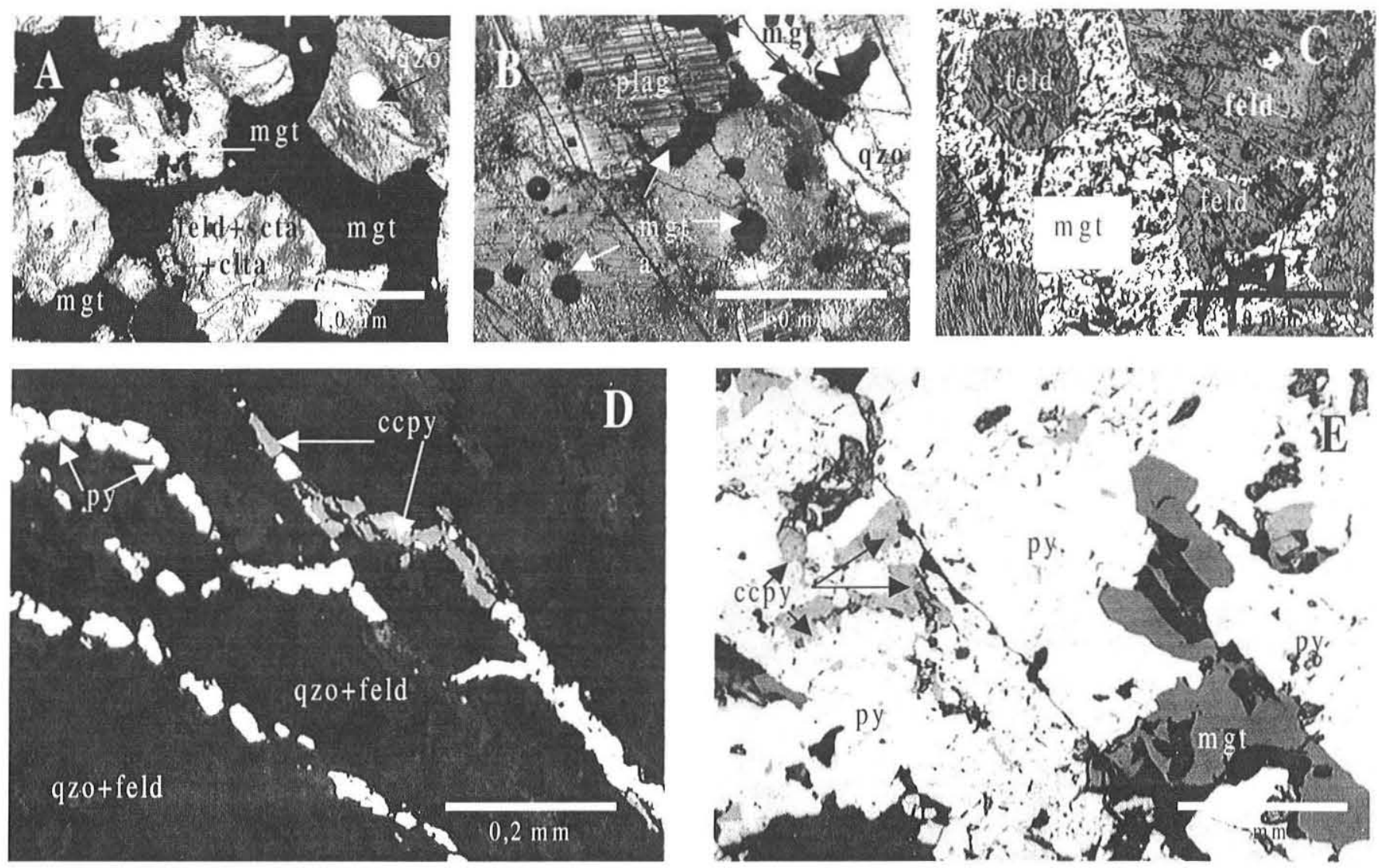

Figura 2 - Fotomicrografias do magnetita-hidrotermalito, rocha encaixante dos corpos mineralizados "poço 1" e "poço 2". (A) Magnetita maciça cimentando cristais hidrotermalizados de feldspato (feldspato K e plagioclásio) e de quartzo. Lâmina delgada, 40x, nicóis $x$. (B) Inclusões de magnetita, com seções de formas ovaladas, dentro de cristais de feldspatos sericitizados e cloritizados $e$ de quartzo. Lâmina delgada, 40x, nicóis $x$. (C) Vênula de magnetita maciça cimentando silicatos. Seção polida, 40x, um nicol. (D) Fissuras dentro do de aglomerados quartzo-feldspáticos preenchidas por pirita e calcopirita. Seção polida, 200x, um nicol. (E) Pirita com micro-inclusões de calcopirita e de magnetita. Seção polida, 400x, um nicol. Abreviações: mgt = magnetita, feld $=$ feldspato (feldspato $\mathrm{K}$ ou plagioclásio), scta $=$ sericita, clta $=$ clorita, py $=$ pirita e ccpy = calcopirita.

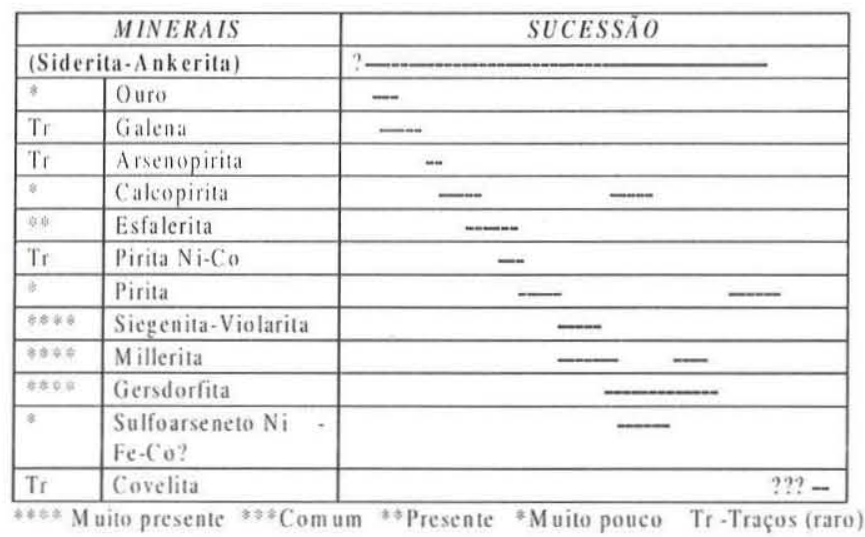

Figura 3 - Sucessão na cristalização dos minerais metálicos, dentro dos corpos mineralizados alongados, quartzocarbonatados, no nível $155 \mathrm{~m}$, na mina Schramm. Total de sulfetos é menor que 0,5\%, em volume.

\begin{tabular}{|c|c|c|}
\hline & MINERAIS & SUCESSÃO \\
\hline (Side & -Ankerita-Quartzo) & $?---$ \\
\hline * & $\begin{array}{l}\text { Ouro + Galena } \\
\text { bismutinífera }\end{array}$ & -- \\
\hline $5+54$ & \begin{tabular}{|l} 
Galena bismutinífera \\
\end{tabular} & - \\
\hline 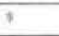 & Cosalita & - \\
\hline+ & Calcopirita & - \\
\hline 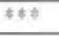 & Esfalerita & $-\cdots$ \\
\hline 7 & \begin{tabular}{|l|} 
Pirita \\
\end{tabular} & - \\
\hline 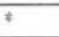 & \begin{tabular}{|l|} 
Pirrotita \\
\end{tabular} & - \\
\hline 4 & \begin{tabular}{|l} 
Gersdorfita \\
\end{tabular} & - \\
\hline $\mathrm{Tr}$ & Covelita & ??"- \\
\hline
\end{tabular}

Figura 4 - Sucessão na cristalização dos minerais metálicos do minério do corpo mineralizado "chaminé I", entre os níveis 155 e 180 m, na mina Schramm. Total de sulfetos é de 5-10\% em volume da rocha. 
terminar que o depósito formou-se a temperaturas entre $227^{\circ} \mathrm{C} \mathrm{e}$ $316^{\circ} \mathrm{C}$ e pressões entre 1,20 e $0,1 \mathrm{~Kb}$. Todas essas características levaram à conclusão de que o modelo genético do depósito do Schramm, é uma variante daquele dos depósitos de ouro em zonas de cisalhamento, ou "depósitos orogênicos", formados em condições de baixas pressão e temperatura, equivalentes às do grau metamórfico fraco a incipiente. As diferenças maiores em relação aos depósitos orogênicos comuns estariam manifestas principalmente nos teores elevados de Au e Ag e na paragênese níquelarseniada, composta sobretudo por siegenita, millerita e gersdorfita, que acompanham o ouro.

Em 2002 e 2003 foram lavrados três corpos mineralizados de alto teor, um deles acima do nível 155 (galeria principal), até o nível $180 \mathrm{~m}$ (chaminé 1), e dois abaixo da galeria principal, até o nível 140 m (poços 1 e 2, Fig. 1). A descrição das rochas expostas e a petrografia de amostras coletadas na chaminé e nos poços revelaram estruturas e paragêneses diferentes daquelas observadas no nível 155. Os objetivos desse trabalho são apresentar a descrição das novas feições observadas, discutir aspectos relacionados às suas gêneses e propor um modelo genético mais detalhado para o minério do depósito.

\section{GEOMETRIA E ROCHAS ENCAIXANTES DOS CORPOS} MINERALIZADOS Os corpos mineralizados "poço I" e "poço 2" têm formas cilíndricas irregulares, sub-verticais, com seções muito variadas. As partes lavradas têm cerca de $15 \mathrm{~m}$ de comprimento, estendendo-se do nível 155 até o nível $140 \mathrm{~m}$, e diâmetros variados entre 2 e $4 \mathrm{~m}$. Estão contidos na interseção entre o veio principal com um corpo tabular, sub-vertical, de uma rocha granitóide foliada, hidrotermalmente muito alterada, magnética, denominada "gnaisse magnético (Figs. 1A e B). A composição desses corpos, observada nas galerias do nível 155 , foi descrita por Biondi et al. (2001, Figs. 4A e D). São misturas irregulares de lentes e bolsões de siderita+ankerita, quartzo e rocha encaixante muito transformada pelo hidrotermalismo. A lavra revelou que eles afilam-se para baixo, transformando-se em uma rede de vênulas de quartzo e de filonetes de carbonato e quartzo (Fig. 1C), com larguras entre 2 a $5 \mathrm{~cm}$, orientados paralelamente ao veio principal (Figs $1 \mathrm{~A} \mathrm{e} \mathrm{C}$ ).

A parte lavrada do corpo mineralizado "chaminé l" estende-se na vertical por $25 \mathrm{~m}$, entre os níveis 155 e 180 (Fig. IC). Está na interseção entre o filão principal e uma lente de granulito ultrabásico (piroxenito) muito carbonatizado e cloritizado (Fig. IC). Tem geometria e composição semelhantes às dos outros corpos de minério, com diâmetro pouco maior, entre 2 e $5 \mathrm{~m}$. No nível 180 o minério desmembra-se em vênulas e filonetes, do mesmo modo que os poços 1 e 2 .

\section{MINERALOGIA DOS CORPOS MINERALIZADOSE SUAS ENCAIXANTES "Gnaisses magnéticos" vs. magnetita} hidrotermalitos Biondi et al.(2001, Figs 3 e 9A e B) reconheceram a presença de "gnaisses magnéticos" na mina Schramm. Suas principais características são: (a) são constituídos por bandas alternadas de quartzo e de magnetita + hematita; (b) os minerais são euédricos ou subédricos, formando textura maciça e poligonizada. Essas feições levaram a interpretar os "gnaisses magnéticos" como metajaspilitos, lenticularizados e preservados dentro dos granulitos.

As rochas que encaixam os corpos mineralizados "poço l" e "poço 2" diferenciam-se dos metajaspilitos devido a serem constituídas por cristais de feldspato sericitizados e cloritizados, cimentados por magnetita, pouca pirita e muito pouca calcopirita (Figs 2A, C e E). A rocha não tem bandamento e é foliada, com foliação sub-vertical imposta pela atitude dos leitos de magnetita. Em locais onde há concentração de quartzo e feldspato, esses minerais contêm inclusões de magnetita que, em lâmina delgada, apresentam formas arredondadas ou ovaladas (Fig. 2B). A pirita e a calcopirita formam vênulas dentro dos silicatos (Fig. 2D), e não há hematita. Há micro-inclusões de magnetita e calcopirita dentro da pirita (Fig. 2E) e de pirita dentro da magnetita, indicando que esses minerais cristalizaram ao mesmo tempo. Essas características identificam magnetita-hidrotermalitos filoneanos, formados pelo cisalhamento de rochas quartzo-feldspáticas e pela cimentação dos cristais por magnetita e sulfetos hidrotermais.

Filões de magnetita-hidrotermalitos ocorrem em diversos locais das galerias do nível 155 , nos poços I e 2 e chaminé 1 . Têm direções semi-paralelas ao filão quartzo-carbonatado principal, mas mergulhos variados, menos constantes que o do filão. É comum que o filão de quartzo e carbonato ocorra dentro do magnetitahidrotermalito. Devido a serem rochas escuras, pretas ou verdes, são difíceis de serem diferenciadas mesoscopicamente dos metajaspilitos, muito menos freqüentes, e confundem-se com o granulito hidrotermalizado, não magnético. Desde o nível 155 até o 180, os corpos mineralizados alongados, com minério com altos teores de Au e de Ag, e os filões quartzo carbonatados não têm magnetita (Figs. 3 e 4). Somente abaixo do nível 155 a magnetita e a hematita passam a fazer parte das paragêneses do minério de alto teor e dos filões (Fig. 5).

Corpos mineralizados "poço 1", "poço 2" e "chaminé 1" A paragênese do minério do nível 155 foi descrita e analisada por Biondi et al. (2001, 2002a), que destacaram o predomínio, entre os sulfetos, de siegenita, millerita e gersdorfita, incomuns em depósitos mesotermais, e a raridade da arsenopirita e da calcopirita, muito comuns em depósitos desse tipo. A figura 3 mostra a paragênese e a sucessão na cristalização dos minerais do minério no nível 155. Notar que o ouro foi o primeiro metal a precipitar, junto à siderita e à ankerita, seguido pela galena e, depois, pela arsenopirita. Galena e arsenopirita ocorrem como traço no minério do nível 155 (Fig. 3). Magnetita, hematita e pirrotita não fazem parte da paragênese do minério.

A partir do nível 155 em direção a superfície, a paragênese do minério muda gradualmente (Fig. 4), como pode ser visto no corpo

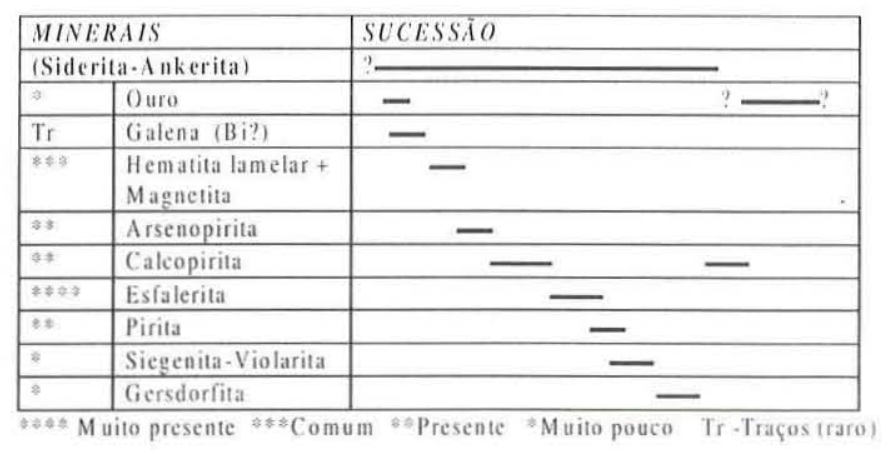

Figura 5 - Sucessão na cristalização dos minerais metálicos dos minérioso dos corpos mineralizados "poçol" e "poço 2", entre os níveis 155 e 140 m, na mina Schramm. Total de sulfetos é de 2 a $5 \%$ em volume da rocha. 

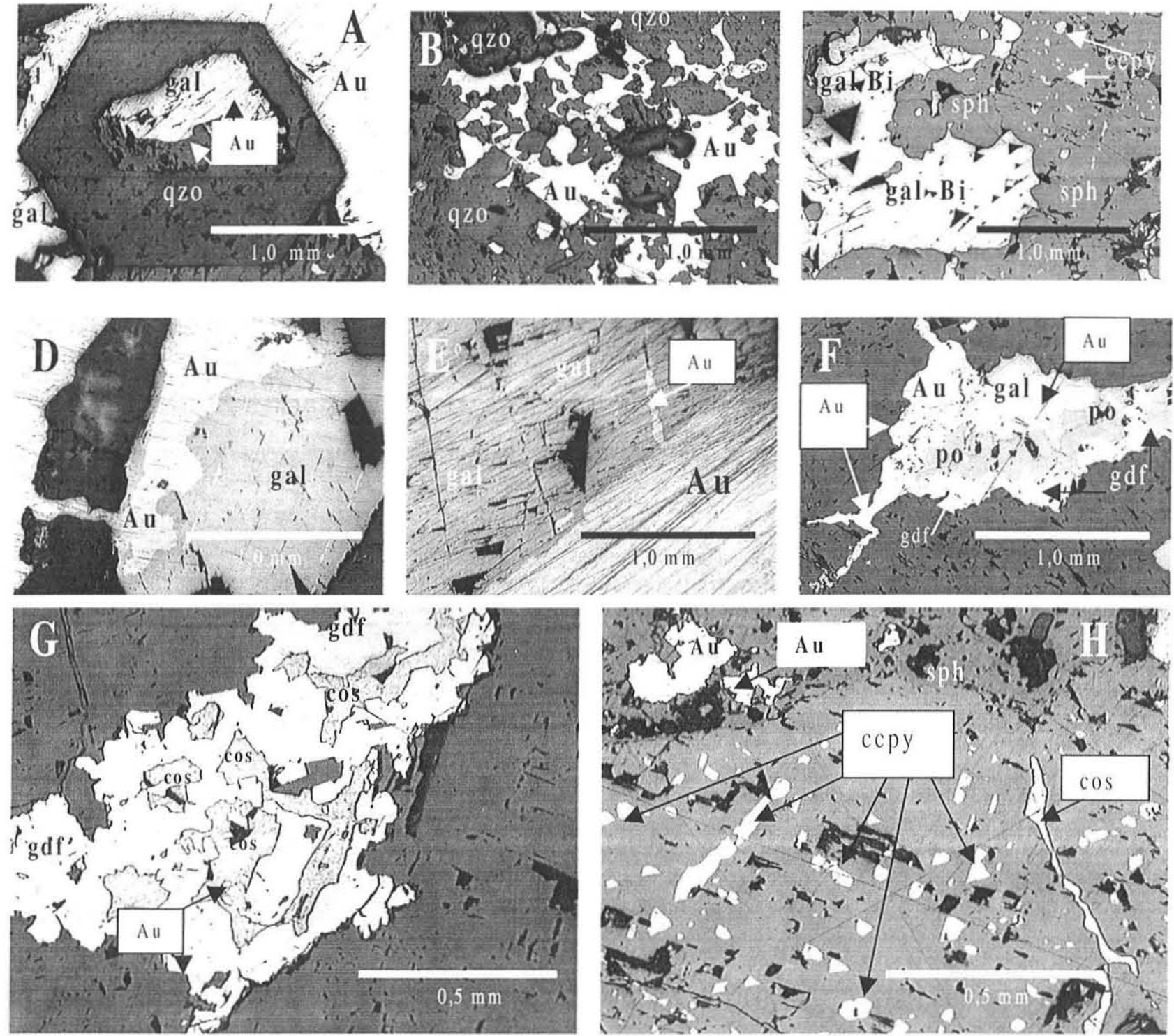

Figura 6 - Fotomicrografias de seções polidas de amostras de minério do corpo mineralizado “chaminé l”. (A) Ouro e galena cristalizados dentro de um prisma de quartzo hialino. 40x, um nicol. (B) Ouro cristalizado dentro de quartzo leitoso.40x, um nicol. (C) Esfalerita com micro-inclusões de calcopirta e inclusões de galena bismutinífera. 40x, um nicol. (D) Ouro envolvido por galena bismutinífera.40x, um nicol. (E) Ouro em clivagem da galena. 40x, um nicol. (F) Ouro, galena, pirrotita e gersdorfita dentro de quartzo. 40x, um nicol. (G) Cosalita dentro de gersdorfita, ambos em meio a siderita. $100 x$, um nicol. (H) Esfalerita com inclusões de ouro, calcopirita e cosalita. $100 x$, um nicol. Abreviações: $\mathrm{gal}=$ galena, qzo $=$ quartzo, $\mathrm{Au}=$ ouro, sph $=$ esfalerita, gal-Bi $=$ galena bismutinífera, pó = pirrotita, $g d f=$ gersdorfita, $c c p y=$ calcopirita e $\cos =$ cosalita .

mineralizado "chaminé I" (Fig. IC). As mudanças mais significativas são as a seguir descritas (Figs. 4 e 6). A quantidade de sulfetos no minério muda de cerca de $0,5 \%$, em volume, no nível 155 , para até $10 \%$ no nível 180 . O ouro, antes descrito somente dentro de carbonato, ocorre cristalizado também dentro de quartzo, tanto em quartzo prismático (Fig. 6A), euédrico e hialino, quanto, muito mais raramente, no leitoso, maciço e anédrico (Fig. 6B). O sulfeto predominante passa a ser a galena bismutinífera, seguida pela esfalerita (Figs. 6C, D, Ee H). A galena cristalizou ao mesmo tempo que o ouro (Fig. 4), dado existirem inclusões de ouro na galena (Figs. 6D, E e F) e vice-versa. Ao final do período de cristalização da galena bismutinífera cristalizou-se a cosalita ( $\left.2 \mathrm{PbS} \mathrm{Bi}_{2} \mathrm{~S}_{3}\right)$, que ocorre dentro da gersdorfita (Fig. 6G) e da esfalerita (Fig. 6H). A pirrotita passa a integrar a paragênese do minério (Fig. 6F), relacionada à galena, à gersdorfita e ao ouro. As quantidades de siegenita e millerita diminuem gradativamente, inexistindo no nível 180. Há diminuição da quantidade de gersdorfita e aumento na da esfalerita. As quantidades de pirita e calcopirita (Fig. 6H) permanecem inalteradas.

Os corpos mineralizados "poço I" e "poço 2" (Fig. IC) praticamente terminam no nível 140, tornando-se filonetes com poucos $\mathrm{cm}$ de largura. A observação desses filonetes (Amostra 2 , Figs 1 C e 7A) revelou feições importantes para a compreensão da gênese do minério: Todo minério abaixo do nível 160, inclusive os 
filonetes do nível 140, estão dentro de magnetita-hidrotermalitos. A sucessão na cristalização dos minerais de ganga pode ser vista com facilidade (Fig. 7.A). Das borda para o centro dos filões cristalizaram: ankerita anédrica $\rightarrow$ siderita prismática, euédrica $\rightarrow$ novamente ankerita, capeando os cristais prismáticos de ankerita $\rightarrow$ clorita (ripidolita-brunsvigita) $\rightarrow$ quartzo hialino euédrico e prismático $\rightarrow$ quartzo leitoso, anédrico. Os hábitos de cristalização e a posição dos minerais indicam que a precipitação dos minerais ocorreu sucessivamente, na ordem descrita, em uma caixa filoneana aberta, preenchida por fluidos. A caixa filoneana foi selada com a precipitação do quartzo leitoso. Em lâmina delgada, a clorita têm hábito "vermiforme" (Figs 8A e B), como a do nível 155 (Biondi $e t$ al. 2001, Figs 8A e D) e parece ser produto da reação do quartzo com a ankerita. No contato entre quartzo e siderita forma-se uma auréola de reação, aparentemente de substituição da siderita por quartzo (Fig. 8C).

Nos poços 1 e 2, nas posições onde foram coletadas as amostras 5 e 6 (Fig. IC). as ramificações dos corpos mineralizados têm entre 0,8 e $1,0 \mathrm{~m}$ de diâmetro. Nesse nível, a esfalerita é o sulfeto mais comum e forma concentrações maciças, centimétricas a decimétricas, inclusas em carbonato e quartzo. Na amostra 5 (Fig. 7B) o ouro é visível mesoscopicamente, incluso na esfalerita cristalizada em meio a quartzo leitoso misturado com ankerita. A siderita é euédrica e está envolvida por duas franjas de hematita + magnetita. A clorita vermicular cristalizou dentro do quartzo, aparentemente sem contato com a siderita. Seções polidas de amostras desse minério contêm magnetita em cristais anédricos bem desenvolvidos, com intercrescimentos de hematita e inclusões de ouro (Fig. 8D). As franjas pretas que envolvem a siderita (Fig. 7B) são de hematita lamelar intercrescida com magnetita (Fig. 8E). Em meio à hematita lamelar cristalizaram a siegenita e o ouro (Fig. 8F). A arsenopirita, rara no nível 155, aumenta de quantidade em direção a base dos corpos mineralizados "poço I" e "poço 2". As inclusões de ouro na arsenopirita são frequentes (Figs 8G). Os aglomerados maciços de cristais de esfalerita têm inclusões de galena e ouro (Fig. 8H) e muitas micro-inclusões de ouro. Nesses aglomerados há, também, fissuras preenchidas por ouro, o que indica que, nesse tipo de minério, houve dois momentos de cristalização do ouro (Fig. 5): Ouro primário, cristalizado dentro do carbonato, junto à galena, e ouro remobilizado (?) cristalizado após a esfalerita, aparentemente também após o quartzo (Fig. 8 I).

Zonalidade vertical no minério da mina Schramm A Fig.9é um esquema que mostra como se distribuem os minerais do minério da mina Schramm entre os níveis 140 e $180 \mathrm{~m}$. Os fatos mais relevantes mostrados nessa figura são: Os teores de ouro e prata variam, mas permanecem muito elevados, entre 500 e 2300 ppm, ao longo de todo o perfil. Do nível 140 para o 180 o minério torna-se gradativamente rico em $\mathrm{Pb}$ e $\mathrm{Bi}$, conforme indicado pela pequena quantidade de galena abaixo do nível 155 e pela grande quantidade de galena bismutinífera e cosalita acima desse nível. Hematita lamelar e magnetita são muito comuns nos minérios dos poços $1 \mathrm{e}$ 2 e desaparecem rapidamente, antes do nível 155. A arsenopirita ocorre no minério dos poços 1 e 2 e não mais cristalizou pouco acima da galeria principal. Esfalerita, calcopirita e pirita ocorrem ao longo de todo o perfil. Embora em quantidades variadas, a esfalerita é, quase sempre, o principal sulfeto do minério. O primeiro aparecimento da pirrotita dá-se pouco acima do nível 155 e ela permanece no minério ao menos até o nível 180. A siegenita participa da paragênese do minério desde o nível 140) até pouco abaixo do 180. Nas proximidades do nível 155, onde o minério tem muito pouco sulfeto ( $\cong 0,5 \%$ em volume), a siegenita é o principal sulfeto do minério, associada à millerita e à gersdorfita. A millerita ocorre somente nas proximidades do nível 155. A gersdorfita ocorre em pequenas quantidades ao longo de todo o perfil, sempre diretamente associada ao ouro. A covelita ocorre como traço desde, aproximadamente, o nível 150 até ao menos o 180. Siderita, ankerita quartzo e clorita (ripidolita-brunsvigita) perfazem a ganga do minério. A grande maior parte do ouro está dentro dos carbonatos, ao longo de todo o perfil. O ouro ocorre também dentro do quartzo, em pequena quantidade, acima do nível 170 e próximo ao nível 140.

DISCUSSÃO Na revisão sobre a química dos fluidos formadores dos depósitos de ouro mesotermais ou "orogênicos", Ridley \&
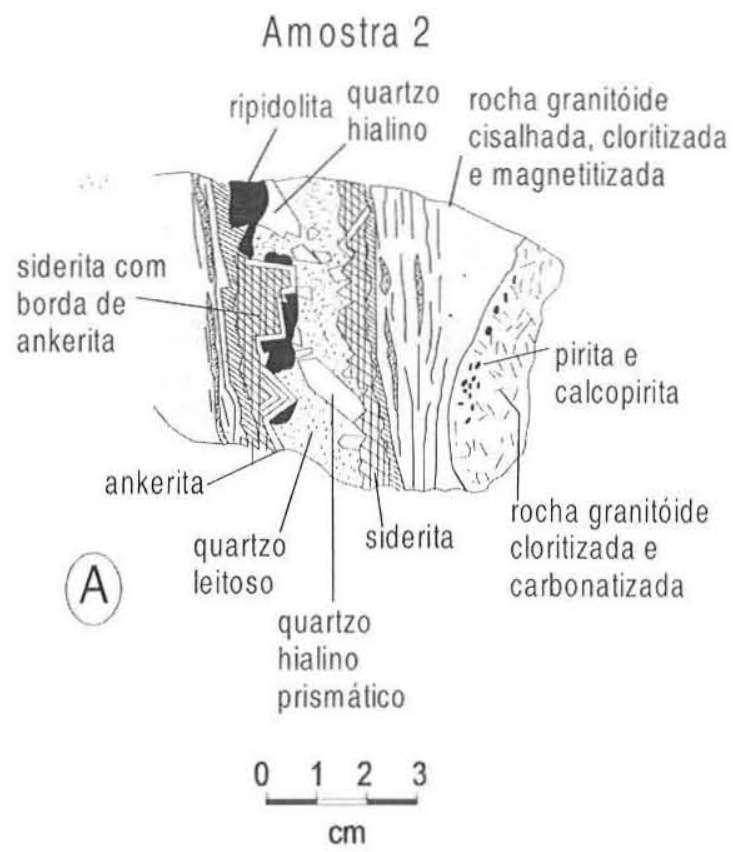

\section{Amostra 5}

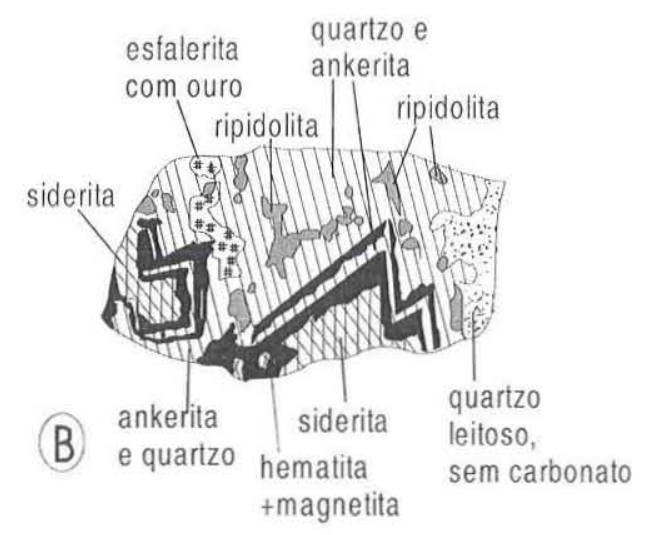

Figura 7 - Feições mesoscópicas das amostras 2 e 5, coletadas nos corpos mineralizados poço I e poço 2, respectivamente (vide Fig. 1C). (A) Amostra 2 - constituição interna de um dos filonetes da extremidade inferior do corpo mineralizado "poço I". (B) Amostra 5 - Feições mesoscópicas do minério de uma das ramificações da parte final do corpo mineralizado "poço 2 ". 

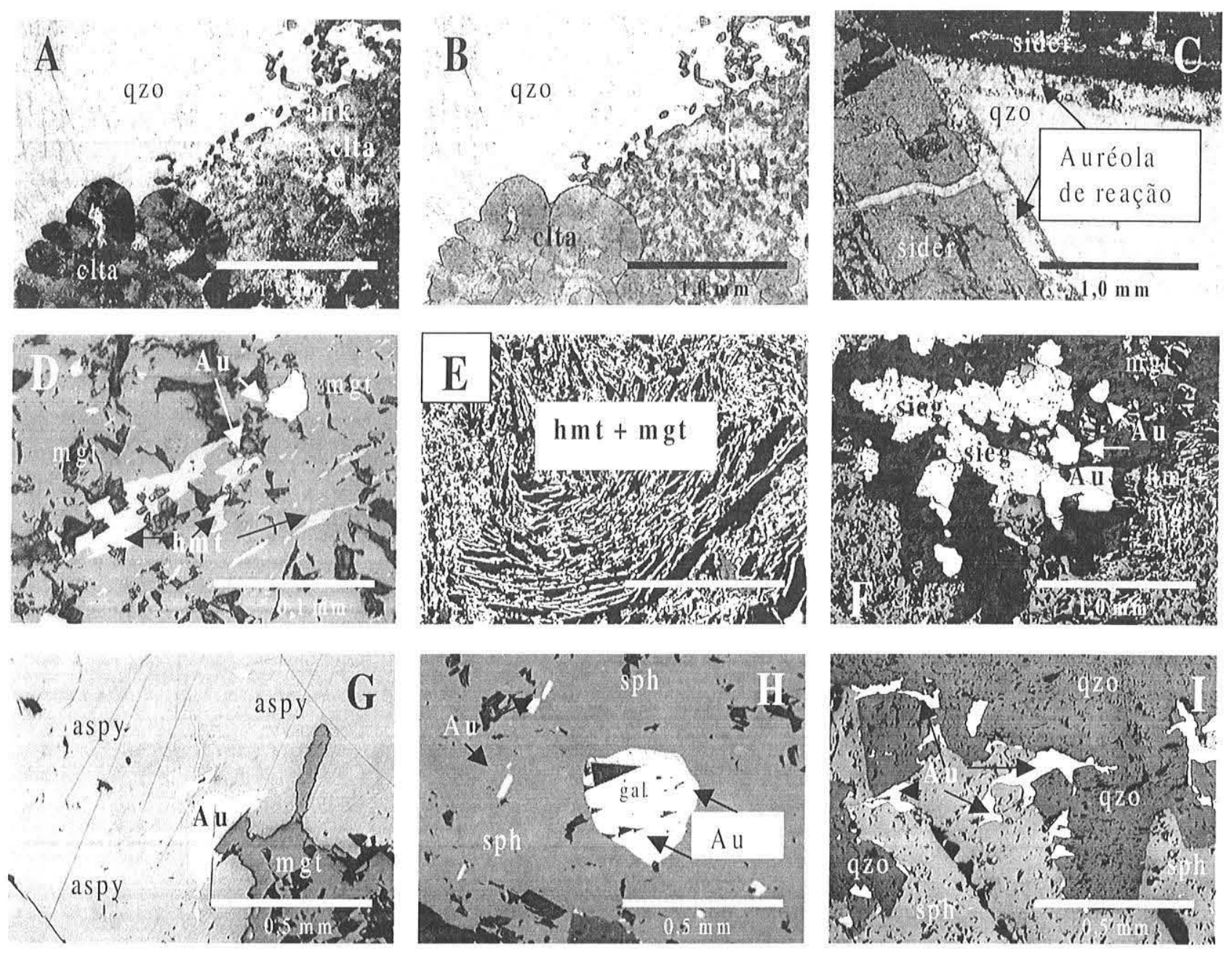

Figura 8 - Fotomicrografias de lâminas delgadas e seções polidas de amostras do minério dos corpos mineralizados "poço I" e “ poço 2". (A) Clorita "vermicular" formada pela reação entre quartzo e ankerita. Lâmina delgada, 40x, nicois X. (B) Igual a (A), com nicóis paralelos. (C) Reação de absorção de siderita por quartzo. Lâmina delgada, 40x, nicóis cruzados. (D) Magnetita com intercrescimento de hematita e inclusões de ouro. Seção polida, 400x, um nicol. (E) Hematita lamelar intercrescida com magnetita, cristalizadas em torno de cristais de siderita. Seção polida, 40x, um nicol.. (F) Siegenita e ouro em meio à concentração de hematita lamelar e magnetita. Seção polida, 40x, um nicol. (G) Grande cristal de arsenopirita com inclusões de ouro e magnetita. Seção polida, 100X, um nicol. (H) Inclusão de ouro e galena dentro de aglomerado maciço de esfalerita. Seção polida, 100x, um nicol. (I) Ouro live dentro de esfalerita e de quartzo. Abreviações: qzo = quartzo, ank $=$ ankerita, sider $=$ siderita, $c$ tta $=$ clorita, $h m t=$ hematita, $m g t=$ magnetita,$a u=$ ouro, sieg $=$ siegenita, gal $=$ galena $e$ sph $=$ esfalerita .

Diamond (2000) concluem que esses fluidos têm composições que refletem mais as interações rocha-fluido ocorridas no caminho percorrido entre as suas fontes e os depósitos que a composição das próprias fontes. Para a maioria dos componentes, parece haver equilíbrio entre a composição do fluido e as das rochas encaixantes, embora não necessariamente a encaixante imediata. Bons exemplos são citados por Ho et al. (1992) e Hagemann et al. (1998), que notaram que os fluidos mineralizadores dos depósitos de ouro do oeste da Austrália mudaram a $\mathrm{fO}_{2}$ sempre que atravessaram rochas metassedimentares grafitosas. Também McKuaig \& Kerrich (1998) notaram que as composições em isótopos de $\mathrm{Pb}$ dos fluidos mineralizadores de Norseman (Canadá) muda conforme a profundidade. Em todos esses casos, foi destacado que a influência de uma dada rocha na composição do fluido é maior quanto mais próximo estiver dessa rocha.
Ridley \& Diamond (2000) determinaram o coeficiente de partição fluido/rocha (Re) de vários elementos encontrados nos fluidos e minérios de depósitos mesotermais. Tendo em conta os Re dos elementos químicos mais comuns do minério do depósito Schramm, fica evidente a história complexa de constituição do fluido mineralizador. O chumbo e o zinco, que têm participação significativa no minério (galena e esfalerita, Fig. 9), são elementos "tracejadores do percurso feito pelos fluidos" (Ridley \& Diamond $2000)$, que revelam as interações fluido/rocha ocorridas durante esse percurso. É improvável que esses elementos tenham sido coletados nos granulitos da região onde se situa a mina e na região não afloram rochas que, normalmente, têm teores de fundo elevados em $\mathrm{Pb}$ e Zn. É, portanto, provável que esses elementos tenham sido adicionados ao fluido em locais distantes do depósito. O Re do arsênio, presente na gersdorfita entre os níveis 140 e 180 
(Fig. 9) e na gersdorfita + arsenopirita entre os níveis 140 e 155, indica que o As seria um elemento precipitado diretamente do fluido mineralizador, com pouca ou nenhuma influência das encaixantes imediatas (Ridley \& Diamond 2000), o que converge para a conclusão anterior, que prevê que o fluido tenha percorrido um caminho longo. Diferentes, entretanto, parecem ser os casos dos potenciais de oxidação $\left(\mathrm{fO}_{2}\right)$ e de sulfetação $\left(\mathrm{aS}_{2}\right)$ do minério do depósito.

Skirrow \& Walshe (2002) notaram que as variações nas composições dos minérios dos vários depósitos de Au-Cu-Bi de Tennant Creek (Austrália) são função das razões entre fO, e aS, dos fluidos mineralizadores, e que $\mathrm{fO}_{2} \mathrm{eaS}_{2}$, por sua vez, dependem das composições das rochas encaixantes em cada um dos depósitos. Os modelos genéticos dos depósitos daquela região indicam que a precipitação de Au e de Bi ocorreu devido a dessulfidação (diminuição de $\mathrm{aS}_{2}$ ) e a oxidação (aumento de $\mathrm{fO}_{2}$ ) de um fluido mineralizador primário reduzido, ocorrida quando esse fluido reagiu com rochas encaixantes ferruginosas ricas em hematita e magnetita. Nesses depósitos foi notado, também, que a elevação do pH causa precipitação de sulfetos e liberação do Au de complexos sulfurosos, o que leva à precipitação de ouro livre. Para demonstrar essas conclusões, Skirrow \& Walshe (2002) calcularam o diagrama de estabilidade dos minerais indicadores do estado de oxi-redução dos minérios dos depósitos estudados (Fig. 10). Dado que as condições de temperatura, de pressão e de composição dos fluidos usadas para calcular esse diagrama são semelhantes às determinadas no depósito Schramm (Biondi \& Xavier 2002, Biondi et al. 2002a e b), esse diagrama pode ser usado para explicar as variações da paragênese do minério (Figs. 3, 4, 5 e 9).

Segundo Burnhan \& Ohmoto (1980), a paragênese hematita + magnetita + calcopirita ( \pm arsenopirta), presente nos minérios dos poços 1 e 2 (Figs. 5 e 6), é típica de ambiente com aS 2 baixa e oxidado, com $\mathrm{fO}_{2}$ entre as dos tampões (buffers) níquel-óxido de níquel (NNO) e hematita-magnetita (HM). Ao contrário, a paragênese pirrotita + pirita $( \pm$ magnetita \pm calcopirita), presente no minério da chaminé 1 (Figs. 3 e 9) indica ambiente reduzido e aS, elevado, com $\mathrm{fO}_{2}$ abaixo da do tampão fayalita-magnetita-quartzo (Rowins 2000).

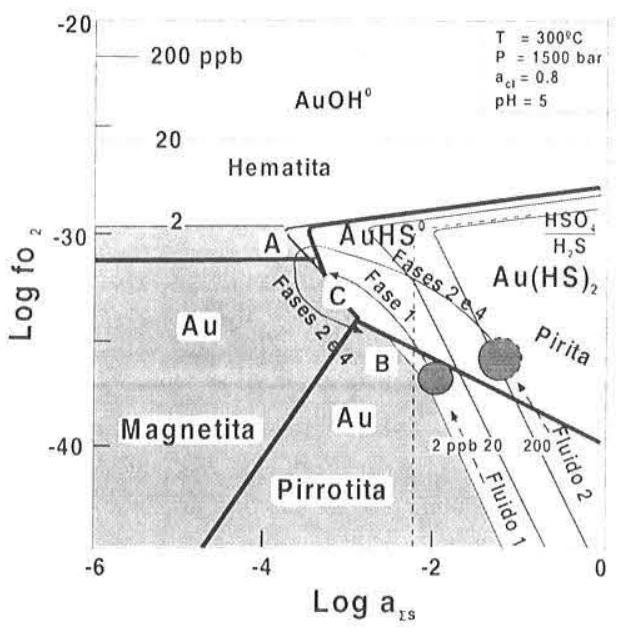

Figura 10 - Diagrama log $\mathrm{fO}_{2}$ vs. a $\mathrm{S}_{2}$ onde constam a solubilidade do Au e as diversas fases do sistema $\mathrm{Fe}-\mathrm{O}-\mathrm{Sa} 300^{\circ} \mathrm{C}$, 1500 bars e $\mathrm{pH}=5$. A área sombreada mais clara corresponde a região de saturação (precipitação) em ouro (Skirrow \& Walshe 2002). As setas mostram as evoluções dos fluidos que precipitaram as paragêneses dos minérios do depósito Schramm entre os niveis 140 e 180. Os círculos sombreados mais escuros correspondem, aproximadamente, as $\log \mathrm{fO}_{2}$, a $\mathrm{S}_{2}$ e concentração de Au dos fluidos no momento em que atingiram o local onde iria se formar o depósito do Schramm. Desses círculos saem linhas, identificadas como "fases 1, 2 e 4" correspondentes às variações nas propriedades dos fluidos conforme precipitaram os minerais formadores do minério. Vide texto para detalhes.

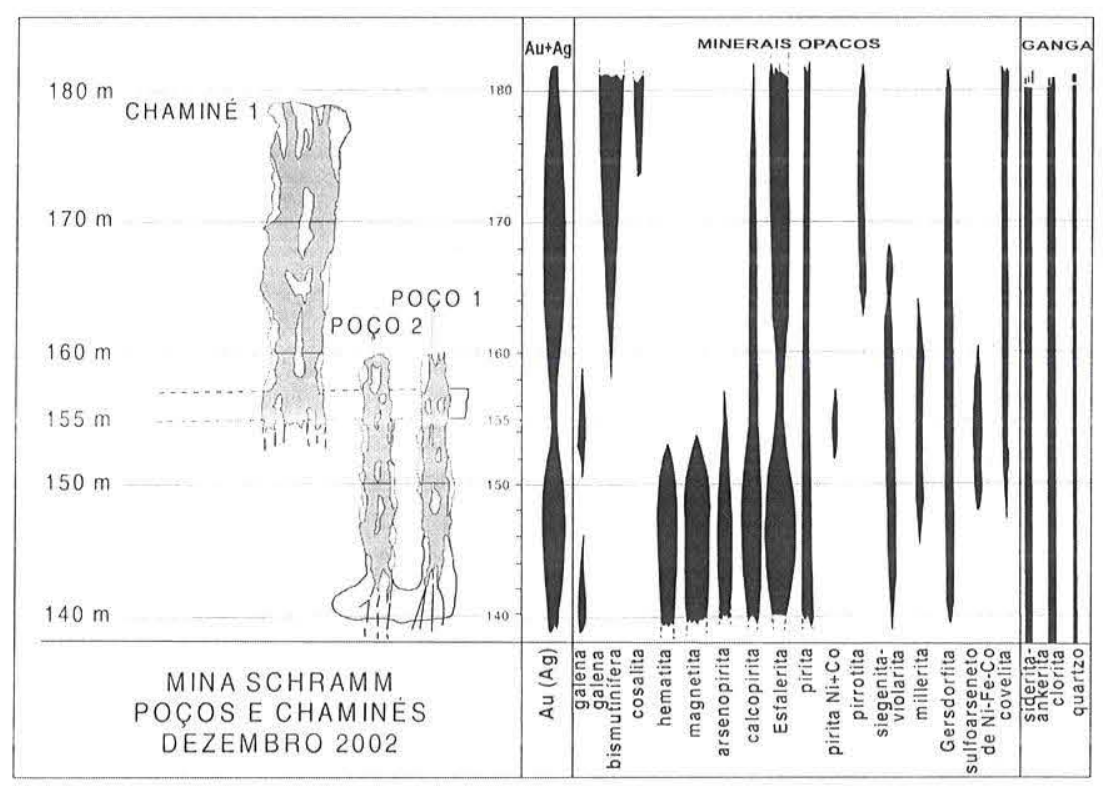

Figura 9 - Esquema mostrando a distribuição dos minerais de minério e ganga nos corpos mineralizados sub-verticais da mina Schramm, entre os níveis 140 e $180 \mathrm{~m}$. A variação na espessura das barras representa, para cada mineral de minério, as quantidades em volume. 
A primeira fase de hidrotermalismo foi a que formou os filões de magnetita-hidrotermalitos com pirita. Nessa fase houve cloritização dos granulitos, cloritização e silicificação dos metajaspilitos e silicificação, cloritizaçãoe sericitização dos gnaisses róseos (Fig. $11 \mathrm{~A}$ ). A orientação e a estrutura foliada sugerem que esses filões formaram-se durante a transição entre a fase sinistral compressional e a fase dextral distensional do cisalhamento principal (Biondi et al. 1992). A clorita hidrotermal dessa fase, analisada por Biondi et al. (2002b), cristalizou a temperaturas próximas de $230^{\circ} \mathrm{C}$.

Cristalizados os magnetita-hidrotemalitos, as fraturas tensionais abriram-se e passaram a receber novos fluidos, provavelmente reduzidos (vide fase 4). Quando em contato com os magnetita-hidrotermalitos (fase 2, Fig. 11 B), reagiram com as
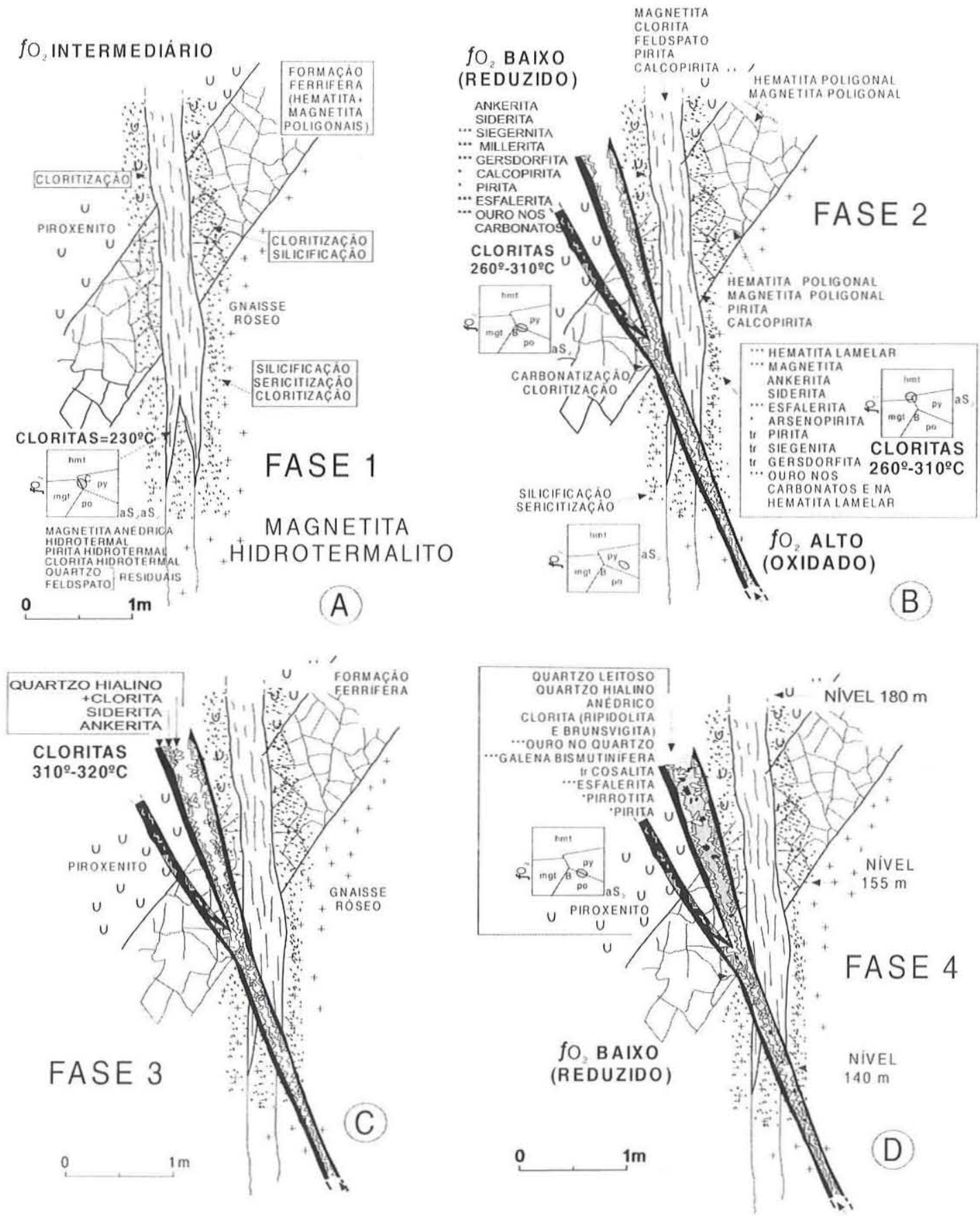

Figura II - Esquemas que representam as quatro fases de formação do depósito de ouro da mina Schramm. (A) Fase I - Formação dos magnetita-hidrotermalitos. (B) Fase 2 - Formação do minério carbonatado e oxidado, dentro dos magnetita-hidrotermalitos, e do minério carbonatado e reduzido, dentro dos granulitos ultrabásicos. (C) Fase 3-Cristalização de cristais euédricos, prismáticos, de quartzo e siderita e de clorita vermicular. (D) Fase 4 - Cristalização do minério reduzido, carbonatado e quartzoso. Os diagramas $\log \mathrm{fO}_{2}$ vs. aS $\mathrm{S}_{2}$ (vide Fig. 7) mostram as características do fluido em cada fase. 
encaixantes e se oxidaram, o que causou a cristalização de carbonato anédrico de Fe e Mg (Fig. 7A), da hematita lamelar, da magnetita e de ouro (Fig. 5). Dentro dos metajaspilitos, cloritizados e silicificados na primeira fase, ou do granulito ultrabásico, o pH foi mais elevado (Biondi et al. 2002b) e, aparentemente, a $\mathrm{fO}_{2}$ foi intermediária, o que proporcionou a cristalização de sulfetos e ouro (Fig. 3). A clorita dessa fase cristalizou a temperaturas entre $260^{\circ} \mathrm{e} 310^{\circ} \mathrm{C}$.

Na fase 3 (Fig. 11 C), a caixa filoneana ficou aberta, o que possibilitou a cristalização de quartzo e carbonato euédricos, prismáticos (Figs 6A, 7A e B e 8C), de clorita vermiforme (Figs 8A e B) a temperaturas entre $310^{\circ}$ e $320^{\circ} \mathrm{C}$ (Biondi et al. 2002b) e pouco ouro. Na quarta e última fase hidrotemal (Fig. 11 D), o fluido mineralizador não pode interagir com as encaixantes devido as paredes do filão estarem cobertas por carbonato, quartzo e clorita das fases anteriores (Fig. 7 A). Nessa condição, isolado e impossibilitado de reagir com as encaixantes, o fluido precipitou uma paragênese reduzida, caracterizada pelo par pirrotita + pirita, ouro livre no carbonato e, em menor quantidade, no quartzo, e bişmuto, contido na galena e na cosalita. A precipitação foi causada pela diminuição de temperatura do fluido, devida a invasão do sistema por água meteórica (Biondi \& Xavier 2002, Biondi et al. $2002 \mathrm{a} \mathrm{e} \mathrm{b),} \mathrm{e} \mathrm{continuou} \mathrm{até} \mathrm{preencher} \mathrm{inteiramente} \mathrm{a} \mathrm{caixa} \mathrm{filoneana.}$

CONCLUSÃO Na Fig. 10 foram grafadas as linhas de variações de $f \mathrm{O}_{2}$ e aS dos fluidos das fases hidrotermais 1 e 2 . O fluido 1 , da fase 1 , precipitou magnetita + pirita e não ouro, o que leva a crer que tenha chegado na região do depósito com teor de Au baixo (p.ex. 2 ppb, na Fig. 10) e evoluído sobre esta linha de concentração, até $\mathrm{C}$, na linha cotética que separa o domínio da magnetita daquele da pirita, fora da zona de saturação em ouro. Neste ponto precipitou magnetita e pirita, até o final do fluxo ou o esgotamento da sua carga catiônica. Nas fases 2 e 4 houve precipitação de ouro. $\mathrm{O}$ fluido 2 (Fig. 10) deve ter chegado ao filão com ouro em solução sulfurosa (p.ex. 200 ppb, na Fig. 10) e evoluiu no sentido da diminuição da solubilidade do ouro (de 200 para 2 ppb), até atingir a zona de saturação no ponto $\mathrm{A}$, dentro de magnetitahidrotermalito. Reagindo com as encaixantes, em um ambiente oxidante, o fluido foi dessulfurizado e oxidado, o que causou a precipitação do ouro junto de carbonato de ferro e magnésio anédrico, hematita lamelar e magnetita (Fig. 11 B, caixa do lado direito). Fora do magnetita-hidrotermalito o mesmo fluido precipitou ouro e sulfetos devido a elevação do pH (Biondi et al. 2002b; Skirrow \& Walshe 2002), em ambiente com $/ \mathrm{O}$, intermediária (Fig. $11 \mathrm{~B}$, caixa do lado esquerdo). Na fase 4 , um fluido igual ao da fase 2 (Biondi \& Xavier 2002), originalmente reduzido, precipitou pirrotita + pirita e ouro em B (Fig.s. 10 e 11 D), quando a temperatura diminuiu devido ao sistema hidrotermal ter sido invadido e dominado por água meteórica, até ser extinto.

Agradecimentos Ao Sr. Dionízio Firszt, proprietário da Mina Schramm, pelo acesso irrestrito ás dependências da Mineração e pela doação das amostras usadas nesse trabalho. Aos Revisores da RBG pelas críticas e sugestões.

\section{Referências}

Biondi J.C., Franke N.D., Carvalho P.R.S., Villanova S.N. 2001. Geologia e petrologia da mina de ouro Schramm (Gaspar-SC). Rev. Bras. Geoc., 31(3):287-298.

Biondi J.C. \& Xavier R.P. 2002. Fluidos associados à mineralização da mina de ouro Schramm, Complexo Granulítico Luis Alves (SC). Rev. Bras. Geoc., 32(2): 235-244.

Biondi J.C., Franke N.D., Carvalho P.R.S., Villanova S.N., Xavier R.P. 2002a. Mina Schramm (SC), com Au, Ag, Ni e As. Im: SBG, XLI Cong. Bras. Geol. (João Pessoa), Anciis, p. 209.

Biondi J.C., Franke N.D., Carvalho P.R.S., Villanova S.N. 2002b. Processo mineralizador e modelo genético da mina de ouro Schramm (SC-Brasil). Rev. Bras. Geoc., 32(4): no prelo.

Burnham C.W. \& Ohmoto H. 1980. Late-stage processes in felsic magmatism. Min. Geol. Special Issue, 8:1-11.

Hagemann S.G., Brown P.E., Ridley J., Stern P., Fournelle J. 1998. Ore petrology, chemistry and timing of electrum in the Archean hypozonal Transvaal lode gold deposit, Western Australia. Econ. Geol., 93:271-291.

Ho S.E., Groves D.I., McNaughton N.J., Mikucki E.J. 1992. The source of ore fluids and solutes in Archean lode gold deposits of western Australia. Jour: Volc. Geothermal Res., 50:173-196.

McCuaig T.C. \& Kerrich R. 1998. P-T-t deformation-fluid characteristics of lode gold deposits: Evidence from alteration systematics. Ore Geol. Rev., 12:381-453.

Ridley J.R. \& Diamond L.W. 2000. Fluid chemistry of orogenic lode gold deposits and implications for genetic models. In: S.G. Hagemann \& P.E. Brown (eds.) Gold in 2000. Reviews in Economic Geology, 13, Society of Economic Geologists, Inc., p.141-162.

Rowins S.M. 2000. Reduced porphyry copper-gold deposits: a new variation on an old theme. Geology, 28(6):49 I-494.

Skirrow R.G. \& Walshe J.L. 2002. Reduced and oxidized Au-Cu-Bi deposits of the Tennant Creek Inlier, Australia: an integrated geologic and chemical model. Econ. Geol., 97:1167-1202.

Manuscrito A-1341

Recebido em 15 de maio de 2003

Revisão dos autores em 30 de janeiro de 2004 Revisão aceita em 11 de fevereiro de 2004 